\title{
Leader Deception Influences on Leader- Member Exchange and Subordinate Organizational Commitment
}

\author{
Jennifer A. Griffith', Shane Connelly', and Chase E. Thiel'
}

\begin{abstract}
Deception is a common and daily occurrence in organizations. Despite this, little is known about how leader deception influences follower perceptions and commitment to the leader and the broader organization. This laboratory experiment uses a low-fidelity simulation task to investigate the effects of leader deception on follower perceptions of leader-member exchange (LMX) and follower commitment to the organization. Moderating effects of financial outcomes that resulted from deception, or who gained from deception, were also tested. Results showed negative effects of leader deception on follower LMX perceptions and affective commitment. Leader financial gain worsened the effects of leader deception on LMX compared with organizational financial gain. Implications of these findings are discussed.
\end{abstract}

\section{Keywords}

deception, gain, leadership behavior, organizational commitment

Corruption at the top levels of organizational leadership is as pervasive as ever, despite the emphasis being placed on the importance of, and need for, ethical leadership (Brown $\&$ Treviño, 2006). One need only to pick up the business section of any major newspaper to see the organizational and sometimes personal havoc wreaked by leaders who have deceived, covered up, or failed to disclose key information. Although there is a growing body of research on ethical and authentic leadership (e.g., Avolio, Gardner, Walumbwa, May, \& Luthans, 2004; Brown \& Treviño, 2006), studies of leader deception have been notably absent from the organizational behavior literature. A number of questions remain about whether, and how, leader deception influences subordinate perceptions and attitudes toward the leader and the organization.

A relationship of trust between leaders and subordinates can be a motivating factor that enhances both employee attitudes and performance (Dirks \& Ferrin, 2001; Mayer, Davis, \& Schoorman, 1995). Trust fosters positive affective reactions (McAllister, 1995), which lays the foundation for affective commitment toward the leader and the organization (e.g., Shore \& Wayne, 1993). Leader deception has the potential to violate trust, thereby undermining the benefits associated with trusting relationships (Keyton \& Smith, 2009; McCornack \& Levine, 1990).

However, Umphress, Ren, Bingham, and Gogus (2009) suggested that leaders and subordinates who engage in deceptive behavior can maintain good relations if the deception leads to mutually satisfying social exchanges. Extant research touches on the importance of understanding how negative leader behavior, such as deception, affects followers and the relationship between leaders and followers (Anand, Ashforth, \& Joshi, 2004; Erickson, Shaw, \& Agabe, 2007; Hollander, 1995). Interestingly, a number of studies have shown that in certain circumstances deception is socially acceptable (Camden, Motley, \& Wilson, 1984; Hooper \& Bell, 1984; Seiter, Bruschke, \& Bai, 2002) and necessary (Frost, 2004). For example, white lies may preserve one's self-image or reduce conflict in a relationship (DePaulo \& Kashy, 1998). DePaulo, Kashy, Kirkendol, Wyer, and Epstein (1996) found that people lie in one of every five social interactions. When leaders see the potential for gain by engaging in deception (or the potential for loss by not engaging in deception), they may more readily justify such behavior.

Given that deception will likely continue in organizational settings, it is important to better understand its impact. This article makes several contributions to our understanding of deception in organizations. First, given that leaders are salient role models who hold positions of responsibility and trust, this study examines the direct effects of leader

'University of Oklahoma, Norman, OK, USA

Corresponding Author:

Jennifer Griffith, Psychology Department, University of Oklahoma, 455 W. Lindsey Street, Dale Hall Tower, Room 705, Norman, OK 73019-2007, USA

Email: jenngriffith@ou.edu 
deception on subordinate perceptions of their relationship with the leader. We also look at whether and how leader deception directly affects subordinate affective commitment to the organization. Third, we examine who gains from leader deception as a key moderator of the relationships of deception to leader-member exchange (LMX) and to subordinate commitment.

In the remainder of the article, we review literature bearing on the issue of leader deception as an important element of the complex social exchanges that occur in organizations. Next, we briefly review the relevant literature on how deception might influence the relationship between a leader and a follower and organizational commitment. The role of financial gain as a moderator is then considered for each of these outcomes. Finally, we describe our experimental research design, procedures, and study results, concluding with discussion of the implications of our findings.

\section{Deception}

Deception is a common occurrence in daily life (DePaulo \& Kashy, 1998). One troubling finding from deception research is that people who recognized that they were engaging in deceptive acts reported that they maintained their behavior because they did not believe they had other viable, truthful alternatives (Lippard, 1988). Often people engage in somewhat socially acceptable deceptive acts categorized as white lies. White lies serve as a mechanism through which people avoid unnecessary or unwanted conflict (Camden et al., 1984; Grover, 1993). Deception is often used to avoid consequences of a hurtful but more truthful statement. Ironically, the consequences of detected deception tend to be similar to those the deceiver intended to avoid such as loss of credibility, loss of trust, and damage to personal relationships (Buller \& Burgoon, 1996; DePaulo, Kashy, Kirkendol, Wyer, \& Epstein, 1996). Not surprisingly, DePaulo and Kashy (1998) reported that lies were told more easily and more frequently to those in casual relationships similar to those found in organizations.

Deception in organizations comes in many shapes and forms, ranging from minor acts, such as exaggerating work experience on a resume, to behavior that has strong implications for an overarching group, such as restricting negative financial information to deter questioning about accounting practices. Payne (2008) asserted that most deception in the workplace consists of exaggeration or lies, and leaders as well as employees at different levels engage in this type of behavior for many different reasons.

Zanzi and O'Neill (2002) noted that unsanctioned political tactics, such as deception, persist with some frequency in organizations as a means of accomplishing organizational objectives or pursuing purely personal ones. It is precisely this type of behavior that permeates an organization to create problems at all levels (Fleming \& Zyglidopoulos, 2008;
Treviño \& Youngblood, 1990). Although it may not appear to cost much in the short term, leader deception may be detrimental in the long term with respect to leader-member relationships and organizational commitment. When individuals distrust their leaders or perceive violation of their psychological contract, they lose faith in their leaders (Robinson \& Rousseau, 1994).

Leader deception and leader-member exchange. LMX theory has been extensively studied in an effort to articulate the nature of dyadic relationships between a leader and each individual follower and study how relationships are formed between subordinates and leaders from a dyadic perspective (Dansereau, Graen, \& Haga, 1975; Graen \& Uhl-Bien, 1995). LMX theory prescribes the differential use of leader resources to develop high-quality relationships with some followers while forming low-quality relationships with others. The follower in a high-quality relationship may be granted more autonomy, given more discretion in terms of decision making, or allowed to perform the better task assignments (Yammarino, 1995). However, because resources are limited, it is necessary that some relationships must be low quality.

The quality of LMX relationships hinges on the social exchanges that occur between the dyad over time. Bauer and Green (1996) asserted that LMX relationships solidify and remain relatively stable across time, but some research has demonstrated the subdimensions that compose LMX, such as trust, commitment, liking, and support, may fluctuate and affect LMX quality. As Brower, Schoorman, and Tan (2000) proposed, LMX is a dynamic, rather than a static, process that is altered by various occurrences, such as violation of trust.

Trust is suggested as a major component within theoretical conceptualizations of LMX (Graen \& Uhl-Bien, 1995). A recent study from Erickson et al. (2007) reported leader actions that 335 subordinates perceived as poor leadership behaviors. These behaviors were categorized as unethical behavior, dishonest behavior, poor interpersonal behavior, inconsistent behavior, disproportionate political behavior, and other behavior types. The same respondents reported consequences of undesirable leadership behaviors. Consequences included, but were not limited to, negative impacts on work relationships, negative affectivity, avoiding work situations, avoiding the leader or the situation, and increases in stress level. Hollander (1995) suggested that leader actions that disregard followers or their psychological contracts, such as those reported in Erickson et al. (2007), lead to or maintain low-quality relationships with subordinates. Relationships in which mutual respect and trust are omitted are unlikely to result in high-quality LMX relationships.

A recent meta-analysis by Dirks and Ferrin (2002) found trust correlated substantially with high-quality LMX relationships, suggesting that trust is, in fact, an important 
component of LMX (see also Graen \& Uhl-Bien, 1995). Butler (1991) suggested that trust is a mutual process, built by honest and open exchange between members of a dyad. When leaders engage in intentional deception with their followers, it is reasonable to assume that once revealed, such behavior will reduce the quality of LMX. Because leaders represent the broader organization in which they are embedded, their actions and decisions affect employee perceptions of, and attachments to, the organization. When leaders violate the trust of their subordinates, this has implications on the nature of perceptions about the organization responsible for hiring and developing the leader. Thus, we propose the following hypothesis:

\section{Hypothesis 1: When leader deception occurs (and is} revealed to followers), followers will report lower quality LMX than when leader deception is absent.

Leader deception and organizational commitment. Generally, organizational commitment reflects the attachment followers feel to their organization and that certain attitudes and behaviors reflect this attachment (Meyer \& Allen, 1984, 1997; Mowday, Steers, \& Porter, 1979). Meyer and Allen (1997) discussed organizational commitment in terms of a three-component model. This model consists of affective commitment, continuance commitment, and normative commitment. Affective commitment is the emotional attachment that employees feel to an organization when they genuinely identify with organizational beliefs and values. In some cases, employees feel that they have invested far more in their organization than they would gain by leaving it. This is called continuance commitment. Employees may also feel morally or ethically obligated to remain in an organization. This component is referred to as normative commitment.

Attitudinal variables and emotions have been shown to play a role in organizational commitment, particularly affective commitment (Mathieu \& Zajac, 1990). For instance, negative reactions toward a leader for acts of deception may enhance distrust toward the leader, leading to lessened affective commitment. This has substantial implications given that contemporary research shows a lack of employee commitment that can lead to tangible outcomes. For instance, Chory and Hubbell (2008) reported that employees may engage in antisocial and deceptive behaviors modeled by their leaders, which could negatively affect the organization.

Although it is true that little evidence exists directly relating leader deception to negative emotional responses, much research has focused on the act of deception in general creating strong negative reactions. McCornack and Levine (1990) suggested that discovery of deception within a relationship tends to be an intense and predominantly negative emotional experience. The reaction is likely to be the strong and negative when the information that was lied about is viewed as important or the act of lying itself significantly changes the relationship. These two factors, rather than strength of the relationship, were found to be the strongest predictors of negative emotional reactions elicited by deception. Acts characterized as leader deception, therefore, can be defined as affective events (Basch \& Fisher, 2000). Affective events theory posits that individuals react emotionally to affective events in the workplace and that those emotional reactions influence attitudes and attitudedriven behavior (Weiss \& Cropanzano, 1996). Deceptive acts on the part of the leader drive negative emotional reactions that have broader implications for employee satisfaction both toward the leader and the organization.

Affective commitment has been researched as the strongest and most potent form of organizational commitment (Jex, 2002). Given the name of this attitudinal form of commitment, it makes sense that much of the research in this domain has found a strong relationship between emotional reactions and one's level of affective commitment (Shore \& Wayne, 1993). Additionally, many researchers have found that affective commitment is positively related to other forms of commitment as well (e.g., Jex, 2002; Meyer \& Allen, 1997; Schoorman, Mayer, \& Davis, 2007). Accordingly, organizational commitment as a whole should be negatively influenced by acts of leader deception that cause negative reactions. In light of this argument, we propose the following hypothesis:

Hypothesis 2: When leader deception occurs (and is revealed to followers), followers will report lower organizational commitment than when leader deception is absent.

\section{Leader Deception and Gain}

Lippard (1988) suggested that there are numerous motivations to lie, such as protection of resources, protection of self, protection of others, avoidance of conflict, manipulation of others, or failure to meet obligations. A closer look at this taxonomy shows that many of the motivations hinge on the potential of gain or loss, both for egotistical and altruistic reasons. After surveying 209 participants, Seiter et al. (2002) found that individuals view deception for the purpose of self-benefit as less acceptable than deception used for the intent to benefit others. Hooper and Bell (1984) reported similar results, with white lies being viewed as more acceptable than deception that is manipulative of others. More broadly, Saxe (1991) proposed that using deception for the social good can be justified and posits that there are some conditions in which lying is acceptable.

Thus, it is possible that leader deception has the potential to be detrimental or advantageous to organizations. Motives underlying leader deception may well be linked to whether a leader engages in more personalized leadership or socialized leadership. Examination of these leadership styles sheds 
some light on why some deception for the greater good may be more accepted than deception for personal gain.

Personalized leaders have egotistical motives that are geared toward accomplishment of personal goals and maximizing positive outcomes for oneself at the expense of followers, groups, or organizations (House \& Howell, 1992; Van Lange \& Kuhlman, 1994). In this form of leadership, followers and, in some cases, organizations are paid little or no regard in terms of the outcomes of deceptive behavior. Socialized leaders have more altruistic motives. Although socialized leaders are concerned with themselves, they have greater concern for others and the collective interest of the organization (House \& Howell, 1992; Van Lange, 1999). Socialized leadership is somewhat akin to transformational leadership, in that the goal of both styles is to empower followers and create positive outcomes for the group (De Cremer, Mayer, van Dijke, Schouten, \& Bardes, 2009; House \& Howell, 1992). Although both socialized and personalized leaders may engage in deceptive behavior, the intention behind and results of the action are important for how followers interpret the outcome.

Consequently, the nature of gain may also moderate the relationship of leader deception to subordinate organizational commitment. When employees see their leader engaging in deceptive, self-serving behavior, they might take this as a cue to reduce their own affective commitment to the organization (Peterson, 2003). Reactions to the deception, including emotional reactions, shape one's thinking about and feelings toward a leader and the organization as a whole. Conversely, when leaders do something that appears to have some value for the greater good, such as the case when socialized leadership is present, individuals tend to have positive emotional experiences that draw them closer to the leader and organization (Lilius et al., 2008). Therefore, when a leader shares the benefits of their deceit, the negative reactions associated with that unethical act may be minimized. However, when benefits are not communal, followers are not as forgiving of negative, self-serving behavior. For instance, Schilling (2009) stated that negative leadership behaviors, including, but not limited to, despotic and exploitative actions, are present in personalized leaders. Such actions result in negative follower attitudes, counterproductive work behaviors (CWBs), and negative organizational outcomes (e.g., poor performance, high turnover rater, unethical organizational climate).

Gain as a moderator. Deception may be viewed as necessary when it protects subordinates from damaging or harmful information. Frost (2004) argued that white lies may sometimes be beneficial and proposes that it may be necessary for leaders to act as "toxin handlers" (p. 115) in which leaders present information in such a way that lessens the emotional blow of sharp criticism from chief executives. By doing so, leaders deliver the desired message without damaging relationships. In these circumstances, leader deception may be viewed as appropriate.

Trust may be maintained if the acts of the leader are seen as having prosocial value. For instance, a recent study found that unethical acts by a leader did not damage LMX when distributive justice was high (Umphress et al., 2009). This suggests, when others perceive that unethical actions will affect everyone, they may be less averse to such behavior. Subordinates who are part of the "in-group" or who benefit from leader dishonesty may maintain positive attitudes toward the leader and company by focusing only on the positive outcome of those acts.

Given that previous research discusses some circumstances in which deception is necessary and viewed as appropriate, it is not uncommon for leaders to strategically use deception when interacting and communicating with followers. Furthermore, the use of rewards and benefits is one mechanism through which leaders may lessen negative reactions toward deception and improve attitudes toward the leader.

It appears, then, that the influence of leader deception on leader-subordinate relationships and subordinate commitment depends on how the deception is interpreted. For example, depending on the motives underlying the deception (e.g., for the greater good vs. for own benefit) subordinates may view leader deception as more or less acceptable. Leader deception might be viewed as self-serving and unfair when the leader gains personally in some way from the deception. However, when a larger group or the organization reaps the benefits, leader deception might be viewed in a more favorable light (Nielsen, 2003) and, consequently, have a less negative impact on leader-subordinate relationships. Furthermore, Anand et al. (2004) suggested that unethical actions or questionable activities are often rationalized or justified to make them seem more acceptable or palatable. Organizational profit or benefit might make it easier to rationalize leader deception as a justifiable means to an end and could potentially improve leader-follower relationships.

Such actions have devastating consequences, such as negative alterations in follower attitudes, CWBs, and negative organizational outcomes (e.g., poor performance, high turnover rater, unethical organizational climate). For instance, De Cremer, van Knippenberg, van Dijke, and Bos (2006) reported an interaction between the nature of leadership behavior (gain for selfish purpose or the group) and follower organizational identification in terms of follower self-esteem. When organization identification was high and the leader engaged in behaviors that benefited the group, follower self-esteem was higher. However, when follower organization identification was low, leadership behavior had no bearing on follower self-esteem.

As previously discussed, research has shown that distributive justice is positively associated with more affective 


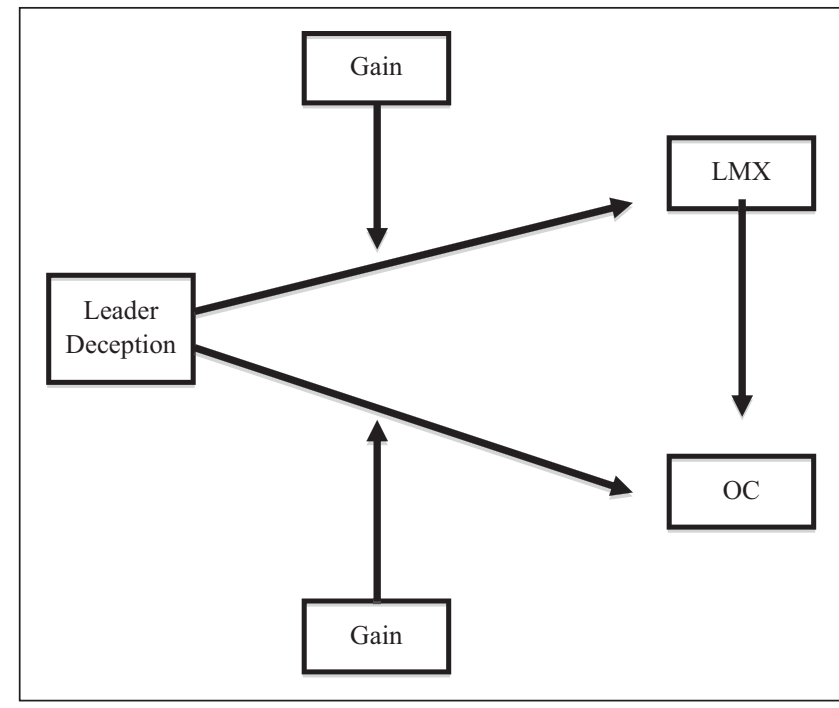

Figure I. Proposed model of moderation

commitment and LMX, suggesting that when subordinates gain they will have higher commitment and more LMX (see Figure 1). The question then becomes, in cases where distributive justice is increased through deceptive leader behavior, how will reactions toward the leader and organization be affected?

We suggest that positive individual reactions to prosocial behaviors will minimize negative reactions associated with leader deception. Affective commitment, then, will be less effected when all individuals gain, because negative emotional reactions to the unethical event will be minimized, or even justified. Likewise, LMX should remain high under these conditions. Thus, we propose the next set of hypotheses:

Hypothesis 3: Leader deception will have a stronger negative relationship with LMX when the leader gains versus the organization.

Hypothesis 4: Leader deception will have a stronger negative relationship with organizational commitment when the leader gains versus the organization.

When the beneficiary of deceptive behavior is revealed, the relationship between deception and LMX may be altered in a different way than the relationship between deception and organization commitment. As the relationship with the leader is more tangible and likely to be immediately affected by deception for personal gain, LMX may suffer significantly as a result. The attitude toward the organization may also be negatively altered; however, subordinates may still find other elements of the organization that influence their decision other than the relationship with the leader, such as salary (Liou, Sylvia, \& Brunk, 1990) or job characteristics (Hackman \& Oldham, 1980). Thus, the negative effect of leader deception may not influence organizational commitment as strongly as LMX. Therefore, we propose our fifth hypothesis:

Hypothesis 5: The moderating effect of gain will differentially affect organizational commitment and LMX such that when the leader gains versus the organization, LMX will be more negatively affected than organizational commitment.

\section{Leader-Member Exchange and Organizational Commitment}

Previous research has proposed that high-quality relationships between a leader and a subordinate can have many positive outcomes for organizations and its employees. The follower in a high-quality relationship may be granted more autonomy, given more discretion in terms of decision making, or allowed to perform the better task assignments (Scandura \& Graen, 1984). A meta-analysis performed by Gerstner and Day (1997) reported LMX had predictive power across many work-related outcomes, including job performance, overall satisfaction, and role clarity. Numerous studies support these findings (see Lagace, 1990; Scandura \& Graen, 1984; Van Knippenberg \& Sleebos, 2006). In addition to the outcomes above, Golden and Veiga (2008) found that LMX was positively correlated with organizational commitment and negatively correlated with turnover intentions. This suggests that the relationship the follower has with the leader may be an important precursor to organizational commitment.

These studies have supplied some evidence to suggest that deceptive behaviors may influence LMX and organizational commitment, and multiple studies have directly related organizational commitment and LMX. Therefore, we expect to replicate similar findings in this study regarding the relationship between LMX and organizational commitment.

Hypothesis 6: LMX will positively predict organizational commitment.

\section{Method}

One hundred and twenty-five undergraduates participated in this study to fulfill a research requirement for an introductory psychology course or to gain extra credit for a course in psychology. Sixty-five percent of participants were female, and on average, participants were 19 years of age. Participants had, on average, 3.11 years of work experience, with work experience ranging from no experience to 30 years. Various majors were represented in this sample (e.g., arts and sciences, humanities, and business). 


\section{Design}

This study used a $2 \times 2$ experimental design in which participants were randomly assigned to conditions. Participants were asked to envision themselves as a member of a marketing team for the duration of the experiment and were provided materials to help them do so. The presence of leader deception (deception vs. no deception) was manipulated along with the type of gain associated with the use of leader deception (leader gain vs. organization gain).

\section{Procedures}

After signing informed consent forms and completing covariate measures, participants read and responded to a series of eight emails containing company information and the leader deception and gain manipulations. In the first email, a member of the marketing team provided the participant with information regarding general company information, the role of the marketing team, and information about the leader with respect to production, marketing, and new-product information. Additionally, participants read information regarding their specific role in the marketing team. In the second email, another member of the marketing teams expresses concern over working long holiday hours due to a new product roll-out. She says she will relay concerns to the leader. Participants then read a third email from the same team member indicating that the leader assured her that no one in the marketing department would be working long hours during the holidays. This sets the stage for the fourth email in which leader deception is manipulated (the leader either lied or was truthful about working during the holidays). In a fifth email, a team member gathers reactions to the leader's email, serving as a leader deception manipulation check. A sixth email provided information to the participant (as a new member of the team) regarding the leader's style of using manipulation and innuendo. This information was the same across all conditions. Gain is manipulated in the seventh email, where participants learn about financial outcomes linked to the leader's decision on the timing of the product roll-out. The eighth email closed out the exchange. Next, participants filled out a questionnaire that contained additional manipulation checks questions, the LMX questions, and the organizational commitment questions.

\section{Manipulations}

The information provided about the leader's negative style of leadership was intended to enhance participants' perceptions that the leader deceived the teams in making those initial assurances. Leader deception is entirely consistent with this particular leader style (see Appendix C).
In the third email, a team member forwards the leader's position on working during the holidays and allays the teams fears about having to work long hours before and during the holiday season because he is not going to rush a new product to market (see Appendix A). However, in the fourth email, the team finds out that the leader intentionally lied to them and that he has recommended speeding up production and marketing efforts that will now require the long hours the team was hoping to avoid (see Appendix A).

Gain was manipulated in the seventh email, in which the team learns that the leader earned a substantial bonus from this stepped up production (leader gain) or that employees in the organization are going to gain from this action through a profit-sharing program in which they are all enrolled (organizational gain; see Appendix B).

\section{Dependent Variables}

Organizational commitment. Organizational commitment was measured using a 5-point Likert-type scale adapted from Mowday et al. (1979), which consisted of 12 of the 13 original items. Analysis of the reliability of this scale yielded an $\alpha$ of .79. This scale contained items assessing the participants' commitment to the organization as a whole, such as willingness to put in more effort than expected, discussion of the organization to individuals outside the organization, and pride of being associated with the company. This included items such as "I really care about the fate of this organization" and "I find that my values and the organization's values are very similar." Additionally, the scale contained reverse-coded items to gauge the possibility of acquiescent responding. One item, "Deciding to work for this organization was a definite mistake on my part," was removed from the scale, as it was not applicable to the study constraints or laboratory setting (i.e., participants did not make the decision to work for the organization in the scenario).

Leader-member exchange. LMX was measured using a Likert-type scale from Liden and Maslyn (1998), which consisted of 11 items. Along with the items from Liden and Maslyn, one additional item, "I would not mind working my hardest for [the leader]," was included in the measure. This item was added to strictly measure follower attitude associated with working for the leader. Analysis of the reliability of this scale yielded an $\alpha$ of .94. The LMX scale consisted of items that assessed the participants' perception of the quality of the relationship with their supervisor, such as respect for their supervisor's knowledge, admiration of their supervisor's professional skills and abilities, and application of extra effort to meet their supervisor's work goals. This scale contained items such as "[The leader] would defend my work actions to a superior, even without complete knowledge of the issue in question" and "I would not mind working my hardest for [the leader]." 


\section{Covariates}

The Big Five Personality Inventory was administered as a covariate in the event that participants' personality would influence their perceptions of the manipulations or the outcomes of interest. The Big Five Personality Inventory is split into extraversion, agreeableness, conscientiousness, neuroticism, and openness and was assessed using John, Donahue, and Kentle's (1991) measure. Analysis of the reliability of each of the subscales yielded coefficient $\alpha$ s of .82 for extraversion, .73 for agreeableness, .76 for conscientiousness, .79 for neuroticism, and .68 for openness.

\section{Manipulation Checks}

The first set of manipulation checks for the deception manipulation was conducted using three expert judges who rated participants' responses to an open-ended item. The item questioned whether they perceived the leader as being truthful or not. Participants are instructed to respond with their "own assessments of [the boss] and what [they] think of his style." These open-ended items were rated on a 5-point Likert-type scale. Manipulation checks of raters yielded interrater reliabilities of .83. Additionally, several manipulation check items were used in addition to the open-ended response item. These items solicited participants for their opinions regarding the deceptiveness of their leaders. Examples of the manipulation check items include "How honest is [your boss]?" and "To what extent did [your boss] mislead your workgroup?" These manipulation check items were measured using a 5-point Likert-type scale. Analysis of the reliability of this scale yielded an $\alpha$ of .84 .

Gain manipulation check items were also rated on a 5-point Likert-type scale by three expert judges. Raters coded the open-ended responses in which participants provide their thoughts regarding "What [they] think about [the result following their leader's deceptive behavior]" in which either the leader receives a large bonus or the company's stock prices increase. These manipulation checks yielded interrater reliabilities of .83. In addition to rated responses, several 5-point Likert-type scale items were used as manipulation checks for gain. Gain manipulation check items included the participants' perception of the results of the boss' actions, such as the local beneficiary of reward (leader) and the global beneficiary of reward (organization). More specifically, participants were asked "To what extent did [your boss's] actions benefit the workgroup?" and "To what extent did [your boss's] actions benefit the organization?" These items served as a check that participants were viewing the party that gains as either the leader or the organization, as they were measured on a common scale. Analysis of the reliability of this scale yielded an alpha of .85.
To evaluate the hypotheses, $2 \times 2$ analysis of covariance (ANCOVA) was used to assess direct effects of leader deception on LMX and organizational commitment, while controlling for personality variables. All personality traits were assessed together, in various pairs, and alone within ANCOVAs. No covariates were significant at the .05 level and thus will be excluded from further analyses and discussion. Additionally, a linear regression was used to assess the relationship between LMX and organizational commitment. Finally, confidence intervals were employed to evaluate the differential moderating effects of gain.

\section{Results}

Analyses

Means, standard deviations, and sample sizes among outcome variables were computed(see Table 1). Intercorrelations among study variables along with internal consistencies of scales and subscales and demographic data are reported in Table 2. Internal consistencies were calculated using Cronbach's alpha.

\section{Manipulation Checks}

Manipulation checks indicated that participants perceived manipulations as intended. A main effect, $t(1,126)=$ $4.11, p<.001$, for the leader deception manipulation was found, indicating that participants viewed the leader in the deception condition $(M=2.79, S D=1.19)$ as more deceptive than those in the nondeception condition $(M=$ 1.57, $S D=1.29$ ).

Participants rated leader gain higher in the leader gain condition $(M=3.45, S D=0.99)$ compared with the organizational gain condition $(M=3.02, S D=0.97), t(1,126)=$ $-2.485, p=.01$. Participants rated group and organizational gain higher in the organizational gain condition $(M=3.46$, $S D=0.95)$ compared with the leader gain condition $(M=$ 2.91, $S D=0.93), t(1,126)=3.30, p<.001$.

\section{Leader Deception}

Results from the analysis of variances (ANOVA) are presented in Table 3. The first ANOVA presented a main effect for leader deception on $\operatorname{LMX}, F(1,124)=7.76, p<.01$. Participants perceived a lower quality LMX, when leader deception was present $(M=2.38, S D=0.87)$ versus absent $(M=2.73, S D=0.76)$, supporting Hypothesis 1. Similarly, leader deception also affected organizational commitment, $F(1,121)=8.93, p<.01$, with participants less committed to the organization when leader deception was present $(M=2.84, S D=0.37)$ versus absent $(M=3.04, S D=0.38)$. Thus, Hypothesis 2 was supported. 
Table I. Means, Standard Deviations, and Sample Sizes of Experimental Conditions

\begin{tabular}{|c|c|c|c|c|c|c|c|c|c|}
\hline \multirow[b]{2}{*}{ Condition } & \multirow[b]{2}{*}{$n$} & \multicolumn{2}{|c|}{ Deception } & \multicolumn{2}{|c|}{ Gain } & \multicolumn{2}{|c|}{$\begin{array}{c}\text { Leader-Member } \\
\text { Exchange }\end{array}$} & \multicolumn{2}{|c|}{$\begin{array}{l}\text { Organizational } \\
\text { Commitment }\end{array}$} \\
\hline & & M & SD & M & SD & M & SD & M & SD \\
\hline Deception & 62 & 2.79 & 1.19 & - & - & 2.38 & 0.87 & 2.84 & 0.37 \\
\hline No deception & 63 & 1.57 & 1.29 & - & - & 2.73 & 0.76 & 3.04 & 0.38 \\
\hline Leader gain & 61 & - & - & 2.91 & 0.92 & 2.32 & 0.82 & 2.91 & 0.40 \\
\hline Organization gain & 64 & - & - & 3.49 & 0.88 & 2.79 & 0.78 & 2.97 & 0.38 \\
\hline Deception $\times$ Leader gain & 29 & - & - & - & - & 1.95 & 0.82 & 2.80 & 0.45 \\
\hline Deception $\times$ Organization gain & 33 & - & - & - & - & 2.76 & 0.73 & 2.88 & 0.29 \\
\hline No deception $\times$ Leader gain & 32 & - & - & - & - & 2.66 & 0.68 & 3.01 & 0.32 \\
\hline No deception $\times$ Organization gain & 31 & - & - & - & - & 2.82 & 0.85 & 3.07 & 0.44 \\
\hline
\end{tabular}

Table 2. Intercorrelations Between Study Variables and Internal Consistencies of Scales

\begin{tabular}{|c|c|c|c|c|c|c|c|c|c|c|}
\hline & 1 & 2 & 3 & 4 & 5 & 6 & 7 & 8 & 9 & 10 \\
\hline I. Leader-member exchange & $(.935)$ & & & & & & & & & \\
\hline 2. Organizational commitment & .403 & $(.789)$ & & & & & & & & \\
\hline 3. Extraversion & -.060 & -.040 & $(.824)$ & & & & & & & \\
\hline 4. Agreeableness & .141 & .084 & .164 & $(.732)$ & & & & & & \\
\hline 5. Conscientiousness & .081 & .080 & .162 & .393 & $(.759)$ & & & & & \\
\hline 6. Neuroticism & .120 & .027 & -.011 & -.302 & -.223 & $(.794)$ & & & & \\
\hline 7. Openness & .007 & -.063 & .146 & .141 & .137 & -.110 & $(.681)$ & & & \\
\hline 8. Age & .111 & .116 & .065 & .080 & .125 & -.033 & .107 & - & & \\
\hline 9. Gender & .039 & -.004 & .031 & .254 & .168 & .241 & -.023 & .048 & - & \\
\hline 10. Work experience & .095 & -.007 & .015 & .057 & .050 & .063 & .139 & .853 & .128 & - \\
\hline
\end{tabular}

Note:Values in italics $=p<.05$, values in boldface $=p>.001$.

Table 3. Effects of Deception and Gain on Follower Relationships With the Leader and the Organization

\begin{tabular}{|c|c|c|c|c|c|c|}
\hline & \multicolumn{3}{|c|}{ Leader-Member Exchange } & \multicolumn{3}{|c|}{ Organizational Commitment } \\
\hline & $F$ & $d f$ & $\eta^{2}$ & $F$ & $d f$ & $\eta^{2}$ \\
\hline Leader deception versus No deception & 7.76 & $\mathrm{I}, 124$ & .06 & 8.93 & 1,121 & .07 \\
\hline Organizational gain versus Leader gain & 13.57 & $\mathrm{I}, \mathrm{I} 24$ & .10 & 0.94 & 1,121 & .01 \\
\hline Deception $\times$ Gain & 5.67 & $\mathrm{I}, \mathrm{I} 24$ & .04 & 0.02 & $\mathrm{I}, 12 \mathrm{I}$ & .00 \\
\hline
\end{tabular}

Note: $\eta^{2}=$ partial eta squared. Values in italics $=p<.05$, values in boldface $=p<.0$ I.

\section{Gain as a Moderator}

The ANOVA also revealed a significant interaction between deception and gain, $F(1,124)=5.67, p<.05$. More specifically, when the organization gained $(M=2.79, S D=$ $0.78)$ rather than the leader $(M=2.32, S D=0.82)$, participants reported higher LMX, $F(1,124)=13.57, p<.01$ (see Figure 2). Participants in the deception conditions reported lower LMX when the leader gained $(M=1.95, S D=0.82)$ than when the organization gained $(M=2.76, S D=0.73)$. However, when no deception was present, levels of LMX stayed relatively stable regardless of whether the leader gained $(M=2.66, S D=0.68)$ or the organization gained ( $M=2.82, S D=0.85)$, confirming Hypothesis 3 . Unexpectedly, gain did not moderate the effect of leader deception on organizational commitment, so Hypothesis 4 was not supported.

Examination of the confidence intervals between leader gain and organizational gain regarding LMX and organizational commitment provides support for the final hypothesis. Although the relationships between both deception and organizational commitment $(\mathrm{CI}=2.88 \pm 0.13, S E=.07)$ and deception and $\operatorname{LMX}(\mathrm{CI}=2.76 \pm 0.27, S E=.13)$ were altered only slightly when organizational gain was present, leader gain affected LMX $(\mathrm{CI}=1.95 \pm 0.28, S E=.14)$ and 


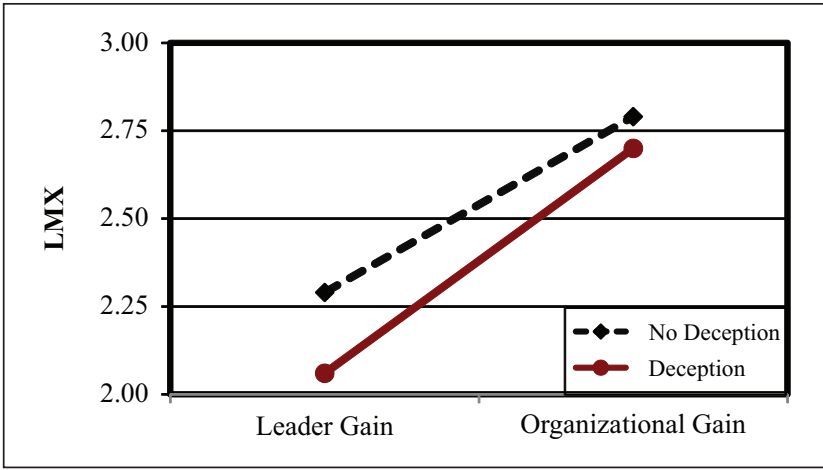

Figure 2. The interaction between leader deception and gain regarding quality of leader-member exchange

organizational commitment $(\mathrm{CI}=2.80 \pm 0.14, S E=.07)$ differentially. That the confidence intervals do not overlap shows support for Hypothesis 5, suggesting that LMX is affected more negatively than organizational commitment when the leader gains versus the organization.

\section{Leader-Member exchange and Organizational Commitment}

Results from the linear regression reveal that $\operatorname{LMX}(B=.188$, $S E=.038)$ positively predicts organizational commitment $\left(R^{2}=.162, p<.001\right)$. Specifically, when LMX is of high quality, organizational commitment was also predicted to be higher, whereas when LMX is of low quality, organizational commitment was also predicted to be low. This finding supports Hypothesis 6.

\section{Discussion}

The findings from this study suggest that leader deception does, in fact, negatively influence perceived quality of LMX and subordinate organizational commitment. LMX quality depended not only on whether or not the leader was deceptive but also on whether the organization or the leader gained. Higher quality LMX was observed when the organization gained.

That leader deception affects organizational commitment and LMX quality negatively lends support to previous research that suggests deception permeates multiple levels of an organization. Treviño and Youngblood (1990) discussed the levels at which deception takes place (e.g., individual, group) by using a "bad apple" versus "bad barrel" analogy. Similar to the phenomenon that Chisholm and Feehan (1977) described in terms of type of deceit, one level of deceit can create the other and vice versa. The notion that a leader's deception affects one's perception of an entire organization has substantial consequences for leaders who engage in unethical or deceptive behaviors. Because leaders are often the visible faces of their organizations, followers often look to them for cues regarding organizational values, norms, and culture (Carson, 2003; Hinrichs, 2007; Oz, 2001). Employees who are more highly committed to their organizations (a) believe in and accept the organizational goals and values, (b) exert effort willingly on behalf of the organization, and (c) desire to maintain their membership within the organization (Mowday et al., 1979). These individuals are also more likely to engage in unethical behaviors that adhere to the organizational culture $(\mathrm{Oz}, 2001)$. Although some evidence suggests that individuals already highly committed to an organization are less likely to engage in unethical behavior (Cullinan, Bline, Farrar, \& Lowe, 2008), leaders who are deceptive, but who do so either for actual organizational gain, or package their deception as such, may be fostering deception in their followers (Hinrichs, 2007).

\section{Theoretical Implications}

Our results indicate that the beneficiary of gain, leader or organization, played a significant role when considering effects on subordinate relationships with the leader. These findings are not entirely consistent with some previous research (see Bruhn, 2005; Morrison \& Robinson, 1997; Robinson \& Rousseau, 1994), which suggested that distrust in the leader created distrust in the organization. Rather, distrust in the leader affected the relationship subordinates have with the leader much more so than subordinate commitment to the organization.

These findings suggest that gain is an important moderator regarding the relationship between leaders and subordinates when deception or other unethical actions occur. Rather than assuming subordinates will react negatively to all deceptive or unethical behavior, these findings suggest subordinates react differently if they perceive that they will gain some reward because of the leader's actions. These findings extend House and Howell's (1992) theory of personalized and socialized leadership into the realm of negative leader behaviors. In other words, associating personalized leader behavior and socialized leader behavior with negative and positive outcomes, respectively, may not always accurately portray the intricacies of the relationship between leaders and followers.

\section{Practical Implications}

As Anand, Ashforth, and Joshi (2004) and Nielsen (2003) suggested, gain was found to be an important element to consider in conjunction with unethical behaviors. Unfortunately, there are some negative implications of these findings that were observable in the aftermath of the Enron scandal. Enron leaders engaged in deceptive behavior, justifying it to employees on the basis that it would create success for the organization. Leaders are more likely to get away with 
deception as long as followers view it as for social good. This is rather disconcerting in light of Oz's (2001) findings that employees high in organizational commitment were more likely to engage in unethical behaviors, particularly unethical behaviors that adhered to the organizational culture.

Our results suggest that when a leader engages in self-serving, deceptive behavior and subordinates become aware of it, leaders will endure the most damage in terms of relationships with subordinates. However, when leader deception occurs, regardless of who gains as a result, subordinate organizational commitment still suffers. To avoid negative organizational consequences as a result of leader deception, organizations must make a concerted effort to foster an ethical culture and ensure that followers are aware of ethical guidelines and organizational standards of conduct.

When organizations discern that leaders engage in deception for personal gain, they should make it clear to employees that this behavior is neither appropriate nor sanctioned. Consequences for such behavior should also be made clear so that employees can maintain trust and confidence in the organization. Depending on the situation, it may be necessary for organizations to reinforce key policies, create new policies, or, in extreme cases, terminate the leader's employment. Additionally, it may be beneficial for organizations to encourage leaders who have engaged in behavior that is deceptive but not deemed extreme to reestablish good relationships with subordinates through training programs that provide leaders with strategies for avoiding future indiscretions and rebuilding supportive and trusting relationships with followers.

\section{Limitations}

Although the current research provides some insight into the relationship among deception, gain, LMX, and organizational commitment, as with many studies involving undergraduates in a laboratory setting, the results attained may not generalize to organizational settings. Students participating in this study may not have engaged in a professional experience in which they were heavily invested, such as viewing a job as a career or livelihood. Furthermore, participants in this study were playing a role rather than actually engaging in workplace behaviors and tasks with coworkers. Low-fidelity simulations have both strengths and weaknesses. In our study, participants received background information concerning their coworkers, organization, their positions, and current projects to give participants a more integrative model of their part within the organization. Responses to the emails provided by participants indicated that they were interested and engaged in the task. However, because participants were not immersed in a dynamic workplace, this element of the study design remains a weakness.

Another potential limitation is that different forms of organizational commitment were not examined. It may be that leader deception and LMX have different effects on affective commitment versus continuance commitment. Additionally, it may be beneficial to examine more fully the effects of organizational gain in the context of leader deception. The phenomenon that individuals may justify deception in the event that the organization is the main beneficiary has strong implications for organizations in terms of organizational culture, values, and norms. As such, these possibilities should be explored to more fully understand the relationship between the variables.

Although the proposed model certainly provides some incremental information regarding relationships among the targeted variables, the model is clearly not inclusive. Models allow for flexibility in terms of parsimony and predictive power, and for the current purposes, it was more relevant to limit the variables to allow for more focus regarding moderated relationships.

\section{Future Research}

Although organizational culture and climate were not the specific focus of this study, these variables may be of interest in future research addressing deceptive behavior in accordance with leader or organizational gain, as previous research has suggested that climate and culture may be related to leadership behaviors (Decelles \& Pfarrer, 2004; Kim, Dansereau, Kim, \& Kim, 2004). Although a certain amount of deception is likely to always exist in organizations, it is essential that deceptive behaviors not result in an organizational culture that widely sanctions all types and levels of deception. More research is needed on whether leader deception of a certain nature and level benefits organizations and the boundary conditions under which these benefits are seen.

Although whether the leader gains or the organization gains may be essential in understanding the impact of unethical or deceptive behaviors, the initial relationship between a subordinate and a leader may be a more important factor in whether employees perceive a leader's deception as acceptable. The strength of the initial leader-subordinate relationship may play a part in whether and how LMX is affected by gain for three reasons. First, followers with a high-quality relationship with leaders may be more forgiving for occasional indiscretions they may commit. Steiner (1997) reported that leader liking is indicative of highquality LMX. Similarly, followers who genuinely like their leader may be more likely to maintain the favorable status in which they hold the leader, regardless of occasional deceptive behavior. Second, followers with a high-quality 
relationship with the leader may interpret leader deception as necessary, such as when the deception spares others of embarrassment or ridicule (Frost, 2004). However, this was clearly not the case in this study. Third, followers may, themselves, engage in self-deception regarding the true impact of a leader's deception (Gray \& Densten, 2007). If followers convince themselves that the leader's untruths are of little significance, as is typical with white lies, they perhaps will overlook the deceit.

It may be important for future research to control for unethical organizational culture as well as LMX in order to fully understand the relationship of leader deception and leader gain with organizational commitment. Additionally, perceived leader attributes may also play a role in subordinate reactions to unethical leader behavior. For instance, would subordinates react differentially following a deceptive act if a leader were initially perceived to be an ethical leader versus an unethical leader? Other concepts that may significantly affect the variables investigated should be included in future modeling processes, such as job characteristics or leader attributes.

\section{Conclusion}

In sum, we hope this research stimulates thinking about leader deception and its influences, both negative and positive. Clearly, some situations exist in which deception is acceptable and necessary. Thus, leaders will likely engage in behaviors that others may deem as deceptive. However, as with many issues enveloped in ethical dilemmas, the line that distinguishes appropriate versus inappropriate use of deceptive behavior is blurred. Given that deception will likely continue to exist in organizations, it is important to better understand its impact on follower and group outcomes in order to avoid making grave mistakes that could be detrimental to LMX relationships or the organization globally.

\section{Appendix A}

\section{Deception Manipulation Emails Leader Deception Condition}

\section{Email 3 \\ Read Message: Inbox \\ From: Carolyn Bakanovic \\ Sent: Aug, 4th 2005 14:58:19 \\ To: Chris@satellite.com,DanM@mkt.satellite .com, Stevenhart@mkt.satellite.com}

Subject: update

Guys, I talked to Thomas this afternoon and told him that we were a bit concerned about the long holiday hours we might have to work to market this new digital music player to Christmas shoppers.
Thomas said, "Don't worry no one in the marketing department will be working long hours this holiday season. We will not begin marketing the new digital music player until February because we will be targeting the spring break crowd."

\section{Email 4}

Read Message: Inbox

From: Thomas

Sent: Aug, 5th 2005 15:18:12

To: marketing.div@satellite.com, product.div @satellite.com, sales.div@satellite.com

Subject: Finite Marketing Project

Satellite team members

As you know the Satellite Vice Presidents just had our monthly meeting. After learning that the production division has the capacity to speed up production for the new digital music players, I recommended that we market the finite product in December to holiday shoppers. Please adjust your project schedules according to this new plan.

\section{No Leader Deception Condition Email 3 \\ Read Message: Inbox \\ From: Carolyn Bakanovic \\ Sent: Aug, 4th 2005 14:58:19 \\ To: Chris@satellite.com,DanM@mkt.satellite .com, Stevenhart@mkt.satellite.com}

Subject: update

Guys, I talked to Thomas this afternoon and told him that we were a bit concerned about the long holiday hours we might have to work to market this new digital music player to Christmas shoppers.

Thomas said, "Don't worry no one in the marketing department will be working long hours this holiday season. We will not begin marketing the new digital music player until February because we will be targeting the spring break crowd."

\section{Email 4}

Read Message: Inbox

From: Thomas

Sent: Aug, 5th 2005 15:18:12

To: marketing.div@satellite.com, product.div @satellite.com, sales.div@satellite.com

Subject: Finite Marketing Project Satellite Team Members

As you know the Satellite Vice Presidents just had our monthly meeting. Although the production division has the capacity to speed up production, I recommended that we stick to the original plan and market the digital music players to spring break and summer vacationers. Please adjust your project schedules to this plan. 


\section{Appendix B}

\section{Gain Manipulation Emails \\ Leader gain condition}

Email 7

Read Message: Inbox

From: Steven Hart

Sent: Aug, 11th 2005 9:36:05

To: Chris@mkt.satellite.com,DanM@satellite .com, Carolyn@mkt.satellite.com

Subject: Latest news

Hey Everyone

Guess what I found out? Thomas received a sizeable salary increase and more retirement benefits. From what I understand, this took place shortly after Thomas made his announcement that the new digital music player would be available by Christmas (deception)/spring break (no deception).

\section{What do you think about this?}

\section{Organizational Gain Condition.}

Email 7

Read Message: Inbox

From: Steven Hart

Sent: Aug, 11th 2005 9:36:05

To: Chris@mkt.satellite.com,DanM@satellite .com, Carolyn@mkt.satellite.com

Subject: Latest news

Hey Everyone

Guess what I found out? Satellite stock prices increased just over $26 \%$ and business analysts are now saying favorable things about Satellite. From what I understand, all of this took place shortly after Thomas made his announcement that the new digital music player will be available to Christmas (deception)/spring break shoppers (no deception).

What do you think about this?

\section{Appendix C}

\section{Leadership Styles Email}

\section{Email 6}

Read Message: Inbox

From: Carolyn Bakanovic

Sent: Aug, 10th 2005 11:18:48

To: Stevenhart@satellite.com, DanM@ satellite.com,Chris@satellite.com

Subject: our boss

Steven-Since you have only been here for a week we haven't had much time to get you up to speed on things. Here some info on our boss Thomas to bear in mind.
Thomas has a tendency to get what he wants even with projects such as finite. Satellite employees are sometimes intimidated by his "do it or else" style of managing.

One time, Thomas was able to effectively silence sales managers who disagreed with marketing dept. goals by aligning himself with key distributors. Thomas has a way of making any shortcomings of his marketing projects seem like they were due to the actions of other managers or departments.

As things like this occur to us, we'll pass along the info. Chris, and Dan - I think it would be a good idea to e-mail Steve your own assessments of Thomas and what you think of his style. We work so well as a team because we all know where the others are coming from.

$\mathrm{Oh}$... and by the way, I was thinking we should consider how to link the finite music player to other personal digital products in our marketing approach.

\section{Declaration of Conflicting Interests}

The author(s) declared no conflicts of interest with respect to the authorship and/or publication of this article.

\section{Funding}

The author(s) received no financial support for the research and/ or authorship of this article.

\section{References}

Anand, V., Ashforth, B. E., \& Joshi, M. (2004). Business as usual: The acceptance and perpetuation of corruption in organizations. Academy of Management Executive, 18, 39-53.

Avolio, B. J., Gardner, W. L., Walumbwa, F. O., May, D. R., \& Luthans, F. (2004). Unlocking the mask: A look at the process by which authentic leaders impact follower attitudes and behaviors. Leadership Quarterly, 15, 801-823.

Basch, J., \& Fisher, C. D. (2000). Added affective events-emotions matrix: A classification of work events and associated emotions. In N. M. Ashkanasy, C. E. Hartel, \& W. J. Zerbe (Eds.), Emotions in the workplace: Research, theory, and practice (pp. 36-48). Westport, CT: Quorum Books/ Greenwood.

Bauer, T. N., \& Green, S. G. (1996). The development of leadermember exchange: A longitudinal test. Academy of Management Journal, 39, 1538-1567.

Brower, H. H., Schoorman, F. D., \& Tan, H. H. (2000). A model of relationship leadership: The integration of trust and leadermember exchange. Leadership Quarterly, 11, 227-250.

Brown, M. E., \& Treviño, L. K. (2006). Ethical leadership: A review and future directions. Leadership Quarterly, 17, 595-616.

Bruhn, J. G. (2005). Looking good, but behaving badly. Health Care Manager, 24, 191-199.

Buller, D. B., \& Burgoon, J. K. (1996). Interpersonal deception theory. Communication Theory, 63, 203-242. 
Butler, J. K. (1991). Toward understanding and measuring conditions of trust: Evolution of a conditions of trust inventory. Journal of Management, 17, 643-663.

Camden, C., Motley, M. T., \& Wilson, A. (1984). White lies as interpersonal communication: A taxonomy and preliminary investigation of social motivations, Western Journal of Communication, 48, 309-325.

Carson, T. L. (2003). Self-interest and business ethics: Some lessons of the recent corporate scandals. Journal of Business Ethics, 43, 389-394.

Chisholm, R. M., \& Feehan, T. D. (1977). The intent to deceive. Journal of Philosophy, 74, 143-159.

Chory, R. M., \& Hubbell, A. P. (2008). Organizational justice and managerial trust as predictors of antisocial employee responses. Communication Quarterly, 56, 357-375.

Cullinan, C., Bline, D., Farrar, R., \& Lowe, D. (2008). Organizationharm vs. organization-gain ethical issues: An exploratory examination of the effects of organizational commitment. Journal of Business Ethics, 80, 225-235.

Dansereau, F., Graen, G., \& Haga, W. J. (1975). A vertical dyad linkage approach to leadership within formal organizations: A longitudinal investigation of the role making process. Organizational Behavior and Human Performance, 13, 46-78.

De Cremer, D., Mayer, D. M., van Dijke, M., Schouten, B. C., \& Bardes, M. (2009). When does self-sacrificial leadership motivate prosocial behavior? It depends on followers' prevention focus. Journal of Applied Psychology, 4, 887-899.

De Cremer, D., van Knippenberg, D., van Dijke, M., \& Bos, A. E. R. (2006). Self-sacrificial leadership and follower self-esteem: When collective identification matters. Group Dynamics: Theory, Research, and Practice, 10, 233-245.

DeCelles, K. A., \& Pfarrer, M. D. (2004). Heroes or villains? Corruption and the charismatic leader. Journal of Leadership \& Organizational Studies, 11, 67-77.

DePaulo, B. M., \& Kashy, D. A. (1998). Everyday lies in close and casual relationships. Journal of Personality and Social Psychology, 74, 63-79.

DePaulo, B. M., Kashy, D. A., Kirkendol, S. E., Wyer, M. M., \& Epstein, J. A. (1996). Lying in everyday life. Journal of Personality and Social Psychology, 70, 979-995.

Dirks, K. T., \& Ferrin, D. L. (2001). The role of trust in organizational settings. Organizational Science, 12, 450-467.

Dirks, K. T., \& Ferrin, D. L. (2002). Trust in leadership: Metaanalytic findings and implications for research and practice. Journal of Applied Psychology, 87, 611-628.

Erickson, A., Shaw, J. B., \& Agabe, Z. (2007). An empirical investigation of the antecedents, behaviors, and outcomes of bad leadership. Journal of Leadership Studies, 1, 26-43.

Fleming, P., \& Zyglidopoulos, S. C. (2008). The escalation of deception in organizations. Journal of Business Ethics, 81, $837-850$

Frost, P. J. (2004). Handling toxic emotions: New challenges for leaders and their organization. Organizational Dynamics, 33 111-127.
Gerstner, C. R., \& Day, D. V. (1997). Meta-analytic review of leader-member exchange theory: Correlates and construct issues. Journal of Applied Psychology, 82, 827-844.

Golden, T. D., \& Veiga, J. F. (2008). The impact of superiorsubordinate relationships on the commitment, job satisfaction, and performance of virtual workers. Leadership Quarterly, 19, 77-88.

Graen, G. B., \& Uhl-Bien, M. (1995). Relationship-based approach to leadership: Development of leader-member exchange (LMX) theory of leadership over 25 years: Applying a multilevel multi-domain perspective. Leadership Quarterly, 6, 219-247.

Gray, J. H., \& Densten, I. L. (2007). How leaders woo followers in the romance of leadership. Applied Psychology, 56, 558-581.

Grover, S. L. (1993). Lying, deceit, and subterfuge: A model of dishonesty in the workplace. Organizational Science, 4, 478-495.

Hackman, J. R., \& Oldham, G. R. (1980). Work redesign. Reading, MA: Addison-Wesley.

Hinrichs, K. T. (2007). Follower propensity to commit crimes of obedience: The role of leadership beliefs. Journal of Leadership \& Organizational Studies, 14, 69-76.

Hollander, E. P. (1995). Ethical challenges in the leader-follower relationship. Business Ethics Quarterly, 5, 55-65.

Hooper, R., \& Bell, R. A. (1984). Broadening the deception construct. Paper presented at the annual meeting of the International Communication Association, San Francisco, CA.

House, R. J., \& Howell, J. M. (1992). Personality and charismatic leadership. Leadership Quarterly, 3, 81-108.

Jex, S. M. (2002). Organizational psychology: A scientist-practitioner approach. New York, NY: Wiley.

John, O. P., Donahue, E. M., \& Kentle, R. L. (1991). The big five inventory-Version $4 a$ and $5 a$. Berkeley: University of California, Berkeley, Institute of Personality and Social Research.

Keyton, J., \& Smith, F. L. (2009). Distrust in leaders: Dimensions, patterns, and emotional intensity. Journal of Leadership \& Organizational Studies, 16, 6-18.

Kim, K., Dansereau, F., Kim, I. S., \& Kim, K. S. (2004). A multiplelevel theory of leadership: The impact of culture as a moderator. Journal of Leadership \& Organizational Studies, 11, 78-92.

Lagace, R. R. (1990, Winter). Leader-member exchange: Antecedents and consequences of the cadre and hired hand. Journal of Personal Selling and Sales Management, 10, 11-19.

Liden, R. C., \& Maslyn, J. M. (1998). Multidimensionality of leader-member exchange: An Empirical assessment through scale development. Journal of Management, 24, 43-72.

Lilius, J. B., Worline, M. C., Maitlis, S., Kanov, J., Dutton, J. E., $\&$ Frost, P. (2008). The contours and consequences of compassion at work. Journal of Organizational Behavior, 29, 193-218.

Lippard, P. V. (1988). “Ask me no questions, I'll tell you no lies": Situational exigencies for interpersonal deception. Western Journal of Speech Communications, 52, 91-103.

Liou, T. K., Sylvia, R. D., \& Brunk, G. (1990). Non-work factors and job satisfaction revisited. Human Relations, 43, 77-86. 
Mathieu, J. E., \& Zajac, D. M. (1990). A review and meta-analysis of the antecedents, correlates, and consequences of organizational commitment. Psychological Bulletin, 108, 171-194.

Mayer, R. C., Davis, J. H., \& Schoorman, F. D. (1995). An integrative model of organizational trust. Academy of Management Review, 20, 709-734.

McAllister, D. J. (1995). Affect- and cognition-based trust as a foundation for interpersonal cooperation in organizations. Academy of Management Journal, 38, 24-59.

McCornack, S. A., \& Levine, T. R. (1990). When lies are uncovered: Emotional and relational outcomes of discovered deception. Communication Monographs, 57, 119-138.

Meyer, J. P., \& Allen, N. J. (1984). Testing the "side-bet theory" of organizational commitment: Some methodological considerations. Journal of Applied Psychology, 69, 372-378.

Meyer, J. P., \& Allen, N. J. (1997). Commitment in the workplace: Theory, research, and application. Thousand Oaks, CA: Sage.

Morrison, E. W., \& Robinson, S. L. (1997). When employees feel betrayed: A model of how psychological contract violation develops. Academy of Management Review, 22, 226-256.

Mowday, R. T., Steers, R. M., \& Porter, L. W. (1979). The measurement of organizational commitment. Journal of Vocational Behavior, 14, 223-247.

Nielsen, R. P. (2003). Corruption networks and implications for ethical corruption reform. Journal of Business Ethics, 42, 125-149.

Oz, E. (2001). Organizational commitment and ethical behavior: An empirical study of information system professionals. Journal of Business Ethics, 34, 137-142.

Payne, H. J. (2008). Targets, strategies, and topics of deception among part-time workers. Employee Relations, 30, 251-263.

Peterson, D. K. (2003). The relationship between ethical pressure, relativistic moral beliefs, and organizational commitment. Journal of Managerial Psychology, 18, 557-572.

Robinson, S. L., \& Rousseau, D. M. (1994). Violating the psychological contract: Not the exception but the norm. Journal of Organizational Behavior, 15, 245-259.

Saxe, L. (1991). Lying: Thoughts of an applied social psychologist. American Psychologist, 46, 409-415.

Scandura, T. A., \& Graen, G. B. (1984). Moderating effects of initial leader-member exchange status on the effects of leadership intervention. Journal of Applied Psychology, 69, 428-436.

Schilling, J. (2009). From ineffectiveness to destruction: A qualitative study on the meaning of negative leadership. Leadership, 5, 102-129.

Schoorman, F. D., Mayer, R. C., \& Davis, J. H. (2007). An integrative model of organizational trust: Past, present, and future. Academy of Management Review, 32, 344-354.

Seiter, J. S., Bruschke, J., \& Bai, C. (2002). The acceptability of deception as a function of perceivers' culture, deceivers' intention, and deceiver-deceived relationship. Western Journal of Communication, 66, 158-180.
Shore, L. M., \& Wayne, S. J. (1993). Commitment and employee behavior: Comparison of affective commitment and continuance commitment with perceived organizational support. Journal of Applied Psychology, 85, 774-780.

Steiner, D. D. (1997). Attributions in leader-member exchanges: Implications for practice. European Journal of Work and Organizational Psychology, 6, 59-71.

Treviño, L. K., \& Youngblood, S. A. (1990). Bad apples in bad barrels: A causal analysis of ethical decision-making behavior. Journal of Applied Psychology, 75, 378-385.

Umphress, E. E., Ren, L. R., Bingham, J. B., \& Gogus, C. I. (2009). The influence of distributive justice on lying for and stealing from a supervisor. Journal of Business Ethics, 86, 507-518.

Van Knippenberg, D., \& Sleebos, E. (2006). Organizational identification versus organizational commitment: Self-definition, social exchanges, and job attitudes. Journal of Organizational Behavior, 27, 571-584.

Van Lange, P. A. M. (1999). The pursuit of joint outcomes and equality in outcomes: An integrative model of social value orientation. Journal of Personality and Social Psychology, 77, 337-349.

Van Lange, P. A. M., \& Kuhlman, D. M. (1994). Social value orientations and impressions of partner's honesty and intelligence: A test of the might versus morality effect. Journal of Personality and Social Psychology, 67, 126-141.

Weiss, H. M., \& Cropanzano, R. (1996). Affective events theory: A theoretical discussion of the structure, causes and consequences of affective experiences at work. Research in Organizational Behavior, 18, 1-74.

Yammarino, F. J. (1995). Dyadic leadership. Journal of Leadership \& Organizational Studies, 2, 50-74.

Zanzi, A., \& O’Neill, R. M. (2002). Sanctioned versus nonsanctioned political tactics. Journal of Managerial Issues, 13, 245-263.

\section{Bios}

Jennifer Griffith is a PhD student at the University of Oklahoma. Her research interests include leadership processes, leader and follower emotions, leader deception, ethical decision-making, and online communication.

Shane Connelly, $\mathrm{PhD}$, is an associate professor at the University of Oklahoma. Her research interests include leadership skills and leader development, the role of emotions and emotion management in leadership and organizational contexts, and ethical decision-making.

Chase Thiel, MS, is a PhD student at the University of Oklahoma. His research interests include leadership and emotion management, ethical decision-making, and training. Currently, Chase is working on his dissertation, examining the influence of context and delivery on leader-facilitated emotion regulation." 